\title{
Effect of dietary cholesterol on erythrocyte peroxidant stress in vitro and in vivo *
}

\author{
Ulana L. Bereza, George J. Brewer and Gretchen M. Hill \\ Department of Human Genetics, The University of Michigan, Ann Arbor, MI 48109 (U.S.A.)
}

(Received January 3rd, 1985)

Key words: Cholesterol diet; Peroxidant stress; Phenylhydrazine; (Erythrocyte)

The effect of dietary variation of plasma cholesterol concentrations on the susceptibility of erythrocytes to in vitro and in vivo peroxidant stress was studied in rats. Malonyldialdehyde, produced in vivo (endogenous malonyldialdehyde) or following in vitro exposure of cells to $10 \mathrm{mM} \mathrm{H} \mathrm{H}_{2}\left(\mathrm{H}_{2} \mathrm{O}_{2}\right.$ malonyldialdehyde), was used as a measure of peroxidant stress. After 5 weeks, the plasma cholesterol concentrations in rats receiving $1.2 \%$ cholesterol $+0.6 \%$ cholic acid in their diet rose to 6-times that of control rats receiving a diet without added cholesterol; at the same time, erythrocyte $\mathrm{H}_{2} \mathrm{O}_{2}$ malonyldialdehyde in the cholesterol-fed rats decreased significantly relative to the control rats. During subsequent exposure of both groups to in vivo peroxidant stress with phenylhydrazine in two separate dose trials, erythrocyte peroxidant stress remained significantly lower in the cholesterol-fed rats: at a dose of $100 \mu \mathrm{mol} / 100 \mathrm{~g}$ body weight, $\mathrm{H}_{2} \mathrm{O}_{2}$ malonyldialdehyde was lower; at a dose of $25 \mu \mathrm{mol} / 100 \mathrm{~g}$ body weight, both endogenous and $\mathrm{H}_{2} \mathrm{O}_{2}$ malonyldialdehyde were lower. Erythrocyte membrane cholesterol concentrations were $12 \%$ higher in the cholesterol-fed rats than in controls. The effects of in vivo peroxidant stress on plasma cholesterol were also studied. In vivo peroxidant stress at the higher dose of phenylhydrazine produced a decrease in plasma cholesterol concentrations of control rats. The lower dose had no effect on this group and the plasma cholesterol concentrations were unchanged in the cholesterol-fed rats during both treatments. The data suggest that elevated plasma cholesterol concentrations are protective against erythrocyte peroxidant stress. The mechanism of cholesterol's protective effect is probably mediated through elevated membrane cholesterol concentrations.

\section{Introduction}

Recently, Jain and Shohet [1] reported that cholesterol is protective against oxidant stress; in vitro cholesterol-enriched erythrocytes were shown to be less susceptible to peroxidant stress than nonenriched cells. It was suggested that cholesterol

\footnotetext{
* A preliminary communication of this work was presented at the Meetings of the Federation of American Societies for Experimental Biology, St. Louis, MO, 1984, and abstracted in Fed. Proc. 43, 796.
}

acts as an oxidant radical scavenger and therefore protects adjacent membrane lipids from oxidative attack.

The observed effect of cholesterol may have implications for patients with sickle cell anemia. Sickle erythrocytes are exposed to increased oxidant stress [2-4] and consequently undergo membrane damage. At the same time, the patients' plasma cholesterol concentrations are low [5]. Since erythrocytes do not synthesize cholesterol and depend for renewal on exchange from the plasma, a low plasma cholesterol may be disadvantageous. If 
so, a treatment approach aimed at increasing the size of the exchangeable pool of cholesterol in the plasma of these patients could be envisaged.

Another implication associated with cholesterol's oxidant radical-scavenging action is that oxygenated derivatives of cholesterol would be formed, many of which have been identified as inhibitors of hepatic cholesterol synthesis [6-9]. It has been suggested $[10,11]$ that oxysterol formation might explain the decreased plasma cholesterol concentrations in patients with sickle cell anemia.

To test these ideas, we have studied the in vivo 'antioxidant' effect of cholesterol in rats. First, plasma cholesterol concentrations were manipulated by dietary supplementations with either cholesterol, cholic acid, plus corn oil or corn oil alone to determine if variations in plasma cholesterol concentrations are associated with variations in the susceptibility of erythrocytes to peroxidant stress during in vitro and in vivo exposures. Second, the plasma cholesterol concentrations during in vivo peroxidant stress were monitored to determine if treatment would result in decreased concentrations of cholesterol in the plasma.

\section{Materials and Methods}

Animals. 20 weanling rats of the Sprague-Dawley strain were purchased from Charles River Laboratories.

Diets. Two diets were used in this study: a control diet consisting of regular rat chow meal (No. 5012, Ralston-Purina, St. Louis, MO) supplemented with $5.0 \%$ (by wt.) corn oil, and a test diet consisting of rat chow supplemented with $1.2 \%$ (by wt.) cholesterol, $0.6 \%$ (by wt.) cholic acid, and $3.8 \%$ (by wt.) corn oil.

The diets were prepared as follows: for the cholesterol-containing diet, an appropriate amount of cholesterol and corn oil were combined and preheated at $250^{\circ} \mathrm{C}$ for $10 \mathrm{~min}$. Cholic acid was premixed with a small quantity of chow and added to the remaining chow together with the cholesterol/corn oil mixture and all the ingredients were mixed for $15 \mathrm{~min}$ in a stainless steel Hobbart paddle mixer. The control diet was prepared similarly except that cholesterol and cholic acid were omitted. Both diets were prepared monthly and stored at $4^{\circ} \mathrm{C}$ at all times.

Food intake was restricted, beginning with 13 $\mathrm{g} /$ day the first week, then followed by $1 \mathrm{~g}$ increments weekly up to $16 \mathrm{~g} /$ day. The food was weighed into individual dishes daily and moistened with distilled water immediately prior to feeding to minimize the spilling of foods by the rats.

Experimental design. The rats were randomly assigned to a dietary treatment group of 10 rats each and housed individually. During the first week, the rats were fed unsupplemented chow to acclimate them to their cages and to the single daily dose feeding schedule of the moistened chow. On the first day of the dietary protocol, after an overnight fast, the animals were weighed, lightly anaesthetized and $2 \mathrm{ml}$ of blood were withdrawn by cardiac puncture into heparinized syringes. Baseline values for hematocrit, hemoglobin, malonyldialdehyde and plasma cholesterol were determined. The diets were begun and continued for the duration of the study. After 5 weeks, blood samples were obtained and assayed as described. Following a 2-week recovery period, both groups were subjected to in vivo peroxidant stress with daily subcutaneous injections of phenylhydrazine at a dose of $100 \mu \mathrm{mol} / 100 \mathrm{~g}$ body weight for 7 days. Phenylhydrazine was dissolved in $0.154 \mathrm{M}$ $\mathrm{NaCl}$ and adjusted to $\mathrm{pH} 7.4$. On the first and subsequent alternate days of injection, 0.25-0.35 $\mathrm{ml}$ blood samples were drawn into heparinized vials by tail clipping for the determination of hemoglobin and hematocrit. On the final day of phenylhydrazine administration, blood samples were obtained by cardiac puncture and analyzed for plasma cholesterol, malonyldialdehyde, hemoglobin and hematocrit. A 2-week recovery period was followed by a second exposure to peroxidant stress with phenylhydrazine at a dose of $25 \mu \mathrm{mol} /$ $100 \mathrm{~g}$ body weight. As described for the higher dose, the rats were monitored for their hematologic status and, on the 7 th day, were bled by cardiac puncture. In addition to the assays described, erythrocyte membrane cholesterol concentrations were determined on samples drawn during the lower dose phenylhydrazine treatment period and on additional samples drawn 2 weeks later.

Assays. Malonyldialdehyde was assayed accord- 
ing to the method of Stocks and Dormandy [12]. Approx. $2 \mathrm{ml}$ of whole blood were spun at $800 \times \mathrm{g}$. the plasma and buffy coat were removed and the cells were washed 2 times with $10 \mathrm{mM}$ Tris buffer in $0.154 \mathrm{M} \mathrm{NaCl}$ ( $\mathrm{pH} \mathrm{7.4)} \mathrm{(the} \mathrm{same} \mathrm{buffer} \mathrm{was}$ used throughout this procedure and will be referred to simply as $10 \mathrm{mM}$ Tris buffer). The washed cells (hematocrit, $50 \%$ ) were adjusted to a hematocrit of $4 \%$ in a $6.0 \mathrm{ml}$ total volume as follows: $0.48 \mathrm{ml}$ of cells were combined with $4.92 \mathrm{ml}$ of $10 \mathrm{mM}$ Tris buffer $+0.6 \mathrm{ml}$ of $10 \mathrm{mM}$ sodium azide dissolved in $10 \mathrm{mM}$ Tris buffer. Following preincubation at $37^{\circ} \mathrm{C}$ for $10 \mathrm{~min}$ in a water bath, $1 \mathrm{ml}$ aliquots of each sample were pipetted into four separate tubes. One duplicate pair was used for endogenous malonyldialdehyde determination to which $1 \mathrm{ml}$ of $10 \mathrm{mM}$ Tris was added; the other duplicate pair was used for $\mathrm{H}_{2} \mathrm{O}_{2}$ malonyldialdehyde determination to which $1 \mathrm{ml}$ of $20 \mathrm{mM} \mathrm{H}_{2} \mathrm{O}_{2}$ was added. The samples were mixed and then incubated at $37^{\circ} \mathrm{C}$ for $1 \mathrm{~h}$. Following addition of $1.0 \mathrm{ml}$ of $28 \%$ trichloroacetic acid/ $1 \mathrm{mM}$ sodium arsenite in 10 $\mathrm{mM}$ Tris buffer, the samples were spun at 33500 $\times g$, for $5 \mathrm{~min}$. To $2.0 \mathrm{ml}$ of the supernatants, 0.5 $\mathrm{ml}$ of $1.0 \%$ thiobarbituric acid/ $50 \mathrm{mM} \mathrm{NaOH}$ in $10 \mathrm{mM}$ Tris buffer was added. The samples were placed in a boiling water bath for 10 min, then cooled rapidly in cold water and the absorbances at 532 and $600 \mathrm{~nm}$ were recorded. The absorbance reading at $600 \mathrm{~nm}$ was subtracted from the reading at $532 \mathrm{~nm}$; this difference and the molar extinction coefficient for malonyldialdehyde were used in calculating malonyldialdehyde concentrations.

Plasma total cholesterol was assayed enzymatically using the Sigma Total Cholesterol Kit (No. 350, St. Louis, MO): $10 \mu \mathrm{l}$ of plasma or standard were combined with $1 \mathrm{ml}$ of cholesterol enzymatic reagent and incubated at $37^{\circ} \mathrm{C}$ for $10 \mathrm{~min}$. The absorbance at $500 \mathrm{~nm}$ was recorded for each sample against a reagent blank.

Erythrocyte membrane cholesterol was determined following extraction by a slightly modified method of Rose and Oklander [13]. First, 1.0 $\mathrm{ml}$ of packed cells was washed three times with 10 $\mathrm{mM}$ Tris buffer in $0.154 \mathrm{M} \mathrm{NaCl}$ (pH 7.4). Then, $1.0 \mathrm{ml}$ distilled water was added and the samples were allowed to stand at $25^{\circ} \mathrm{C}$ for $15 \mathrm{~min}$. Extraction proceeded with the addition of $7.0 \mathrm{ml}$ chloro- form followed by a $1 \mathrm{~h}$ standing period, then the addition of $11.0 \mathrm{ml}$ isopropanol and an additional $1 \mathrm{~h}$ standing period. The extract was spun at $1100 \times g$ for $30 \mathrm{~min}$, the residue was discarded and cholesterol in the supernatant was measured by a modified Lieberman-Burchard procedure for serum or plasma cholesterol (Sigma, unpublished data). Either $1.0 \mathrm{ml}$ of extract or $1.0 \mathrm{ml}$ of cholesterol standard (diluted $1: 1, \mathrm{v} / \mathrm{v}$ with isopropanol) was evaporated to dryness under nitrogen. To the residues, $0.1 \mathrm{ml}$ of water and $5.9 \mathrm{ml}$ of cholesterol color reagent (Sigma No. 965-60) were added and the peak absorbance at $640 \mathrm{~nm}$ was recorded for each sample against a reagent blank containing $0.1 \mathrm{ml}$ water and $5.9 \mathrm{ml}$ of cholesterol color reagent.

Hemoglobin was assayed by the cyanmethemoglobin method. During periods of in vivo peroxidant stress with phenylhydrazine, significant amounts of oxidized hemoglobin were formed which increased the turbidity of the samples. In this case, the diluted samples were first centrifuged at $3000 \times g$ for $5 \mathrm{~min}$ and the absorbance of the supernatant at $540 \mathrm{~nm}$ was recorded. Hematocrits were measured by the microcapillary method.

Reagents. Reagents were obtained from the following sources: cholic acid (3,7,12-trihydroxycholanic acid), cholesterol (5(6)-cholesten-3-ol) USP grade, phenylhydrazine hydrochloride. cholesterol color reagent (Lieberman-Burchard. modified), total cholesterol enzymatic kit, and cholesterol aqueous standard from Sigma Chemical Company, St. Louis, MO; chloroform. methanol, and ethyl ether from Mallinckrodt. Paris. KY; all other reagents were of reagent grade. The corn oil was of commercial grade.

\section{Results}

\section{Body growth}

A daily record of food consumption was maintained for each rat. Since the rats were on a restricted, single-dose feeding regimen, they readily ate all of their food with one exception which occurred during the period of in vivo peroxidant stress with the higher dose of phenylhydrazine. In this instance, two or three rats in each group showed slight decreases in appetite, which returned to normal after the injections were stopped. 


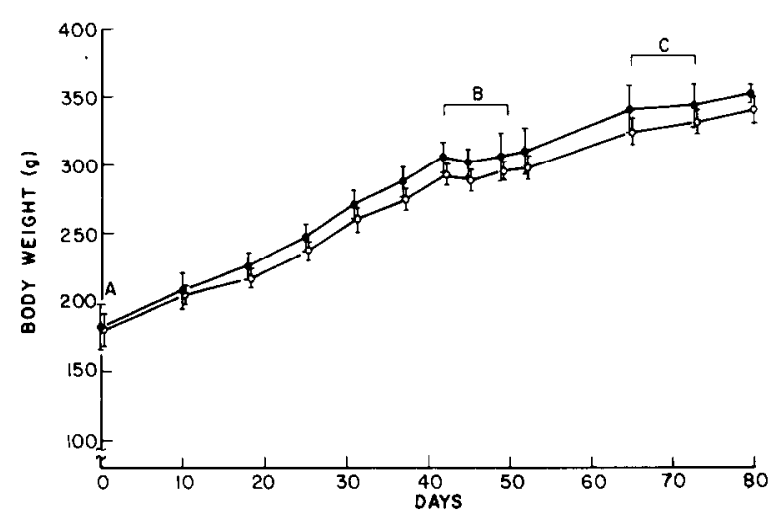

Fig. 1. Body weights of two dietary groups before and during in vivo peroxidant stress. control group (diet containing 5.0\% corn oil), $O$, cholesterol group (diet containing $1.2 \%$ cholesterol, $0.6 \%$ cholic acid and $3.8 \%$ corn oil), A, beginning of dietary protocol; B, period of in vivo peroxidant stress with $100 \mu \mathrm{mol}$ phenylhydrazine $/ 100 \mathrm{~g}$ body weight; $\mathrm{C}$, period of in vivo peroxidant stress with $25 \mu \mathrm{mol}$ phenylhydrazine $/ 100 \mathrm{~g}$ body weight.

This loss in appetite was not detectable as an abnormal body weight, since the weights increased steadily throughout the study and did not differ for the two groups (Fig. 1).

\section{Plasma cholesterol}

After 5 weeks of dietary protocol, the plasma cholesterol concentrations of both groups rose relative to initial levels; however, the increase was more than 10-fold greater in the group consuming the diet supplemented with cholesterol and cholic acid (Table I).

Both groups were subsequently exposed to in
TABLE I

EFFECTS OF DIETS ON PLASMA CHOLESTEROL CONCENTRATIONS

Plasma cholesterol was assayed enzymatically using Sigma Total Cholesterol Kit. Results are means \pm S.D., ${ }^{*} P<0.001$.

\begin{tabular}{llcc}
\hline Day & Dietary group & $n$ & $\begin{array}{l}\text { Plasma cholesterol } \\
(\mathrm{mg} / \mathrm{dl})\end{array}$ \\
\hline 1 & $\begin{array}{l}\text { control } \\
\text { cholesterol }\end{array}$ & 10 & $38.7 \pm 4.3$ \\
& 10 & $40.6 \pm 7.4$ \\
35 & $\begin{array}{l}\text { control } \\
\text { cholesterol }\end{array}$ & 10 & $58.4 \pm 8.4$ \\
& & 10 & $304.2 \pm 128.1^{*}$ \\
\hline
\end{tabular}

vivo peroxidant stress with phenylhydrazine in two separate dose trials. During the first treatment with $100 \mu \mathrm{mol} / 100 \mathrm{~g}$ body weight, the plasma cholesterol concentrations of the control group decreased relative to pretreatment levels, although significant only at $P<0.08$; no change occurred in the cholesterol-fed group (Table IIA). During the second treatment with $25 \mu \mathrm{mol} / 100 \mathrm{~g}$ body weight, the plasma cholesterol concentrations remained unchanged in both groups (Table IIB).

\section{Erythrocyte peroxidant stress}

The amount of thiobarbituric acid-reactive substance formed, referred to here as malonyldialdehyde, was used as a measure of erythrocyte peroxidant stress. Two determinations of oxidant stress were made on each sample: endogenous malonyldialdehyde which refers to malonyldialdehyde generated by cells without added in vitro peroxidant stress and $\mathrm{H}_{2} \mathrm{O}_{2}$ malonyldialdehyde which is a

TABLE II

\section{PLASMA CHOLESTEROL CONCENTRATIONS DURING PHENYLHYDRAZINE TREATMENTS}

Phenylhydrazine was used to induce in vivo oxidant stress in two separate 7-day dose trials. Phenylhydrazine solutions, prepared in $0.154 \mathrm{M} \mathrm{NaCl}$ and adjusted to $\mathrm{pH} 7.4$, were administered daily by subcutancous injections. Plasma cholesterol was assayed on days 1 and 7 of each treatment period. The assay and dietary protocols are given in Materials and Methods. Results are means \pm S.D.

\begin{tabular}{|c|c|c|c|c|}
\hline \multirow[t]{2}{*}{ Phenylhydrazine } & \multirow[t]{2}{*}{ Dietary group } & \multirow[t]{2}{*}{$n$} & \multicolumn{2}{|c|}{ Plasma cholesterol (mg/dl) } \\
\hline & & & pretreatment & during treatment \\
\hline A. $100 \mu \mathrm{mol} / 100 \mathrm{~g}$ body wt. & $\begin{array}{l}\text { control } \\
\text { cholesterol }\end{array}$ & $\begin{array}{l}10 \\
10\end{array}$ & $\begin{array}{rr}61.3 \pm & 7.7 \\
245.7 \pm 110.7\end{array}$ & $\begin{array}{r}53.6 \pm 10.9 \\
255.6 \pm 134.3\end{array}$ \\
\hline B. $25 \mu \mathrm{mol} / 100 \mathrm{~g}$ body wt. & $\begin{array}{l}\text { control } \\
\text { cholesterol }\end{array}$ & $\begin{array}{r}10 \\
9\end{array}$ & $\begin{array}{r}53.7 \pm 10.7 \\
195.2 \pm 29.8\end{array}$ & $\begin{array}{r}52.9 \pm \\
190.1 \pm 74.6\end{array}$ \\
\hline
\end{tabular}


measure of the susceptibility of erythocytes to peroxidant stress during in vitro exposure of cells to $10 \mathrm{mM} \mathrm{H}_{2} \mathrm{O}_{2}$.

Before the dietary protocols were begun, the values for $\mathrm{H}_{2} \mathrm{O}_{2}$ malonyldialdehyde were the same for the two groups; endogenous malonyldialdehyde values were more variable, the difference between groups reaching significance $(P<0.05)$ (Table III). However, after the rats had been on their respective diets for 5 weeks, endogenous malonyldialdehyde values declined in both groups and were not different from one another (Table III) $\mathrm{H}_{2} \mathrm{O}_{2}$ malonyldialdehyde, on the other hand. decreased significantly $(P<0.001)$ in the cholesterol-fed group.

In vivo peroxidant stress with phenylhydrazine ( $100 \mu \mathrm{mol} / 100 \mathrm{~g}$ body weight) produced a significant rise in both measures of malonyldialdehyde in both groups. Endogenous malonyldialdehyde did not differ for the dietary groups, while $\mathrm{H}_{2} \mathrm{O}_{2}$ malonyldialdehyde was again significantly lower (84.5\% of control; $P<0.025)$ in the cholesterol-fed group (Table III). Both groups became severely anemic during this treatment as seen by the low hemoglobin and hematocrit values in Table III. During a recovery period which followed this treatment, both groups regained normal hematologic status (data not shown).

During the second exposure to in vivo peroxi- dant stress at a reduced dose of phenylhydrazine ( $25 \mu \mathrm{mol} / 100 \mathrm{~g}$ body weight), hemolysis was less severe than at the higher dose. At this time, both endogenous and $\mathrm{H}_{2} \mathrm{O}_{2}$ malonyldialdehyde were significantly lower $(P<0.005$ and $P<0.001$, respectively) in the cholesterol-fed rats relative to controls (Table III). Endogenous malonyldialdehyde was approx. $25 \%$ lower, and $\mathrm{H}_{2} \mathrm{O}_{2}$ malonyldialdehyde approx. $12 \%$ lower in the cholesterol-fed rats.

\section{Membrane cholesterol}

Erythrocyte membrane cholesterol concentrations were determined after the final period of in vivo peroxidant stress using $25 \mu \mathrm{mol} / 100 \mathrm{~g}$ body weight. Pooled samples were used for the analysis. The results showed that the erythrocytes from the cholesterol-fed group had substantially higher membrane cholesterol concentrations than the control group (1.12 vs. $0.92 \mathrm{mg} / \mathrm{ml}$ packed cells). A duplicate assay, performed on samples drawn two weeks later, gave similar results. Since only two samples were analyzed for each group, statistical analysis was not carried out.

\section{Discussion}

The primary objective of this study was to determine if dietary variation of plasma cholesterol

\section{TABLE III}

\section{ERYTHROCYTE MALONYLDIALDEHYDE FORMATION BEFORE AND DURING IN VIVO PEROXIDANT STRESS}

Two assays were performed on each sample: for endogenous malonyldialdehyde (MDA), $1 \mathrm{ml}$ of a $4 \%$ erythrocyte suspension (see Materials and Methods) was combined with $1 \mathrm{ml}$ of $10 \mathrm{mM}$ Tris buffer in $0.154 \mathrm{M} \mathrm{NaCl}$ ( $\mathrm{pH} 7.4$ ); for $\mathrm{H}_{2} \mathrm{O}_{2}$ malonyldialdehyde 1 ml of the same suspension was combined with $1 \mathrm{ml}$ of $20 \mathrm{mM} \mathrm{H}_{2} \mathrm{O}_{2}$ in $10 \mathrm{mM}$ Tris buffer. The samples were then assayed according to Stocks and Dormandy [12]. The results are means \pm S.D. Het, hematocrit; Hb, hemoglobin.

\begin{tabular}{|c|c|c|c|c|c|c|}
\hline Period & Dietary group & $n$ & $\begin{array}{l}\mathrm{Hct} \\
(\%)\end{array}$ & $\begin{array}{l}\mathrm{Hb} \\
(\mathrm{g} \%)\end{array}$ & $\begin{array}{l}\text { Fndogenous MDA } \\
(\mu \mathrm{mol} / \mathrm{g} \mathrm{Hb})\end{array}$ & $\begin{array}{l}\mathrm{H}_{2} \mathrm{O}_{2} \mathrm{MDA} \\
(\mu \mathrm{mol} / \mathrm{g} \mathrm{Hb})\end{array}$ \\
\hline Baseline & $\begin{array}{l}\text { control } \\
\text { cholesterol }\end{array}$ & $\begin{array}{l}10 \\
10\end{array}$ & $\begin{array}{l}44.3 \pm 2.3 \\
43.2 \pm 1.6\end{array}$ & $\begin{array}{l}16.2 \pm 1.4 \\
15.4 \pm 1.2\end{array}$ & $\begin{array}{l}0.061 \pm 0.010 \\
0.051 \pm 0.009 *\end{array}$ & $\begin{array}{l}1.957 \pm 0.076 \\
1.919 \pm 0.073\end{array}$ \\
\hline Diet for 5 weeks & $\begin{array}{l}\text { control } \\
\text { cholesterol }\end{array}$ & $\begin{array}{l}10 \\
10\end{array}$ & $\begin{array}{l}43.4 \pm 3.2 \\
42.2 \pm 2.3\end{array}$ & $\begin{array}{l}14.1 \pm 1.2 \\
14.0 \pm 0.8\end{array}$ & $\begin{array}{l}0.032 \pm 0.005 \\
0.028 \pm 0.005\end{array}$ & $\begin{array}{l}1.873 \pm 0.155 \\
1.610 \pm 0.076^{* * * *}\end{array}$ \\
\hline $\begin{array}{l}\text { Phenylhydrazine } \\
(100 \mu \text { mol } / 100 \mathrm{~g} \text { body wt.) }\end{array}$ & $\begin{array}{l}\text { control } \\
\text { cholesterol }\end{array}$ & $\begin{array}{l}10 \\
10\end{array}$ & $\begin{array}{l}30.3 \pm 3.2 \\
27.7 \pm 2.8\end{array}$ & $\begin{array}{l}6.4 \pm 0.8 \\
6.4 \pm 0.5\end{array}$ & $\begin{array}{l}0.090 \pm 0.010 \\
0.086 \pm 0.022^{b}\end{array}$ & $\begin{array}{l}3.269 \pm 0.282^{a} \\
2.768 \pm 0.402^{c \cdot * *}\end{array}$ \\
\hline $\begin{array}{l}\text { Phenylhydrazine } \\
(25 \mu \mathrm{mol} / 100 \mathrm{~g} \text { body wt.) }\end{array}$ & $\begin{array}{l}\text { control } \\
\text { cholesterol }\end{array}$ & $\begin{array}{r}9 \\
10\end{array}$ & $\begin{array}{l}38.4 \pm 1.8 \\
35.4 \pm 1.6\end{array}$ & $\begin{array}{l}11.1 \pm 0.5 \\
10.4 \pm 0.6\end{array}$ & $\begin{array}{l}0.039 \pm 0.007^{\mathrm{a}} \\
0.029 \pm 0.003^{\mathrm{a} * * * *}\end{array}$ & $\begin{array}{l}1.694 \pm 0.112^{h} \\
1.498 \pm 0.064^{h, * * * *}\end{array}$ \\
\hline
\end{tabular}

${ }^{\mathrm{a}} n=8:{ }^{\mathrm{b}} n=9 ;{ }^{\mathrm{c}} n=7 .{ }^{*} P<0.05 ;{ }^{* *} P<0.025 ;{ }^{* *} P<0.005 ;{ }^{* * * *} P<0.001$; for cholesterol vs. control groups. 
concentrations would be associated with variation in susceptibility of erythrocytes to peroxidant stress. Before the dietary treatments were begun, both groups were evaluated for endogenous and $\mathrm{H}_{2} \mathrm{O}_{2}$ malonyldialdehyde (Table III, baseline period). A small, but significant mean difference in endogenous malonyldialdehyde between groups was detected which likely reflected the heterogeneity of the rats used in these studies. After 5 weeks of dietary protocol, the rats receiving a diet supplemented with $1.2 \%$ cholesterol and $0.6 \%$ cholic acid had 6-fold higher plasma cholesterol concentrations than rats receiving the control diet without added cholesterol (Table I). With the rise in cholesterol both measures of malonyldialdehyde decreased in both dietary teatment groups (Table III). Endogenous malonyldialdehyde values at this time were no longer different between the groups (Table III). In contrast, the mean $\mathrm{H}_{2} \mathrm{O}_{2}$ malonyldialdehyde for cholesterol-fed rats was decreased $14 \%$ relative to the mean for control rats, that is, the erythrocytes of the cholesterol-fed rats were less susceptible to in vitro peroxidant stress (Table III). A similar decrease in the susceptibility of erythrocytes to peroxidant stress was observed in the cholesterol-fed rats following in vivo peroxidant stress with phenylhydrazine at a dose of 100 $\mu \mathrm{mol} / 100 \mathrm{~g}$ body weight (Table III). During a second, milder, exposure to in vivo peroxidant stress with phenylhydrazine $(25 \mu \mathrm{mol} / 100 \mathrm{~g}$ body weight), both measures of erythrocyte oxidant stress were lower in the cholesterol-fed group; endogenous malonyldialdehyde was approx. 25\% lower, and $\mathrm{H}_{2} \mathrm{O}_{2}$ malonyldialdehyde approx. $12 \%$ lower relative to control group values (Table III). A rise in erythrocyte membrane cholesterol concentrations paralleled the rise in plasma cholesterol of the cholesterol-fed group. The results of duplicate assays revealed an average $12 \%$ higher membrane cholesterol concentration in rats of this group.

The data suggest that elevated plasma cholesterol levels are associated with decreased in vitro and in vivo peroxidant stress of erythrocytes. This effect is probably mediated by elevated membrane cholesterol concentrations as shown by Jain and Shohet [1] with in vitro cholesterol-enriched human erythrocytes. The mechanism by which membrane cholesterol protects is uncertain. One possibility is that increased incorporation of cholesterol results in changes in the packing of phospholipids in such a way as to make them less accessible to oxidant radical attack. Another possibility, initially proposed by Jain and Shohet [1], is that cholesterol acts as an oxidant radical scavenger and thus protects adjacent membrane lipids from oxidation. A decrease in the degree of erythrocyte hemolysis would be expected from an elevated membrane cholesterol based on a reduction of membrane damage from lipid peroxidation. In the present study, hemolysis did not differ between groups during the oxidant stress of phenylhydrazine administration. It is possible that the rats in the cholesterol-treated group were partially protected against hemolysis, but that differences in hemolytic rate as evaluated by hemoglobin and hematocrit measurements were obscured by an increased erythroid response in the control rats. Measures of erythroid response or direct measures of hemolytic rate were not carried out in this study.

If cholesterol was acting as a scavenger for oxidant radicals, oxidized derivatives of cholesterol would be formed, many of which have been identified as inhibitors of hepatic cholesterol synthesis. Accordingly, a secondary objective of this study was to determine if in vivo peroxidant stress would result in decreased plasma cholesterol concentrations. During in vivo peroxidant stress at the higher dose of phenylhydrazine, the plasma cholesterol concentrations of control rats decreased, though not significantly and, during the lower dose phenylhydrazine treatment, the plasma cholesterol concentrations remained unchanged. The phenylhydrazine treatment had no effect on plasma cholesterol of cholesterol-fed rats, as expected, since dietary cholesterol is itself inhibitory [14-16]. The present data from the control group, thus, is inconclusive with regard to increased oxygenated sterol formation during in vivo peroxidant stress. Irrespective of the mechanism by which cholesterol exerts its effect, our work indicates that elevated levels in the plasma are protective against erythrocyte peroxidant stress.

The possible effect of corn oil on erythrocyte peroxidant stress was considered. It was added to the diets for caloric balance: $5 \%$ to the control diets and $3.8 \%$ to diets containing $1.2 \%$ cholesterol 
(or approx. $10.5 \%$ and $8.0 \%$ of calories for control and test diets, respectively). Corn oil was chosen because it is a traditionally used source of fat in studies of dietary fat and because there is information in the literature on its effects. It has been shown that the fatty acid composition of various tissues, including the erythrocytes, can be altered by dietary fats [17-20]. Dietary corn oil, in particular, results in increases in membrane linoleic and arachidonic acids. Since linoleic acid can undergo lipid peroxidation in vivo [21], this raises the question whether the difference in the amount of corn oil added to the two diets resulted in a difference in the amount of linoleic acid incorporated into the membrane and consequently accounts for the difference in erythrocyte oxidant stress. Data from studies on the effect of dietary corn oil on the erythrocyte membrane fatty acid profile [17-19] indicate that, in general, amounts of corn oil greater than the $5 \%$ used here are necessary to produce significant changes in erythrocyte fatty acids. Further, dietary corn oil at any level does not affect either the total lipid content or the proportion of lipid classes in the erythrocyte membrane.

In light of these results, it is unlikely that the 3.8 or $5.0 \%$ corn oil used in this study would have caused a significant increase in the linoleic acid content of erythrocytes. Even less likely is that the $1.2 \%$ difference between the diets of the two groups would lead to a large enough difference in the incorporation of linoleic acid to influence lipid peroxidation. Endogenous malonyldialdehyde did not differ for the two dietary groups after 5 weeks of diets. Further, in Jain and Shohet's study [1], manipulations of erythrocyte membrane cholesterol concentrations were carried out in vitro without the effects of fatty acids.

To summarize the results of our study: (1) they provide further evidence for cholesterol's protective effect against erythrocyte oxidant stress, (2) they demonstrate this protective effect in an animal model before and during in vivo peroxidant stress, and (3) they show that cholesterol's protective effect can be manipulated through dietary variations of plasma cholesterol concentration. These observations may have clinical relevance, for example, to patients with sickle cell anemia in whom plasma cholesterol concentrations are characteristically lower than normal, and erythrocytes un- dergo increased oxidant stress. The present data suggest that an elevated plasma cholesterol in these patients would ameliorate some of the membrane damage associated with the peroxidation of membrane lipids.

\section{Acknowledgements}

The authors thank Dr. Bohr from the Department of Physiology, The University of Michigan, for the use of his mixer, and Michael Pape for his excellent technical assistance. This work was supported in part by the Herrick, Sage and Irvin Foundations.

\section{References}

1 Jain, S.K. and Shohet, S.B. (1981) Clin. Res. 29, 336A

2 Chiu. D. and Lubin, B. (1979) J. Lab. Clin. Med. 94, $542-548$

3 Chiu, D., Lubin, B. and Shohet, S.B. (1979) Br. J. Haematol. 41, 223-234

4 Das. S.K. and Nair, R.C. (1980) Br. J. Haematol. 44, 87-92

5 Lubin, B., Krauss, R., Klemen, K., Simmons, E. and Chiu. D. (1979) Blood 54, Suppl. 1, 30A

6 Raulston, D.L., Mishaw, C.O., Paris, E.J. and Schroepfer, G.J., Jr. (1976) Biochem. Biophys. Res. Commun. 71, 984

7 Schroepfer, G.J., Jr., Monger. D., Taylor, A.S.. Chamberlain, J.S., Parish, E.J., Kisic, A. and Kandutsch, A.A. (1977) Biochem. Biophys. Res. Commun. 78, 1227-1233

8 Kandutsch, A.A., Chen, H.W. and Heiniger, H. (1978) Science 201, 498-501

9 Schroepfer, G.J., Jr. (1981) Annu. Rev. Biochem. 50. $585-621$

10 Bereza, U.L. and Brewer, G.J. (1984) Fed. Proc. 43, 796

11 Payne, P.H., Stone, W.L. and Adhikary, P.K. (1984) Fed. Proc. 43, 394

12 Stocks, J. and Dormandy, T.L. (1971) Br. J. Haematol. 20 , 95-111

13 Rose, H.G. and Oklander, M. (1968) J. Lipid Res. 6, 428-431

14 Beher, W.T., Baker, G.D. and Penney, D.G. (1963) J. Nutr. $79,523-530$

15 Raicht, R.F., Cohen, B.I., Shefer, S. and Mosbach, E.H. (1975) Biochim. Biophys. Acta $388,374-384$

16 Bochenek, W. and Rodgers, J.B. (1978) Biochim. Biophys. Acta 528, 1-16

17 Witting, L.A., Harvey, C.C., Century, B. and Horwitt, M.K. (1961) J. Lipid Res. 2, 412-418

18 Mohrhauer, H. and Holman, R.T. (1963) J. Lipid Res. 4, $346-350$

19 Farquhar, J.W. and Ahrens, E.H. (1963) J. Clin. Invest. 42, $675-685$

20 De Gier, J. and Van Deenan, L.L.M. (1964) Biochim. Biophys. Acta 84, 294-304

21 Iritani, N., Fukuda, E. and Kitamura, Y. (1980) J. Nutr 110, $924-930$ 